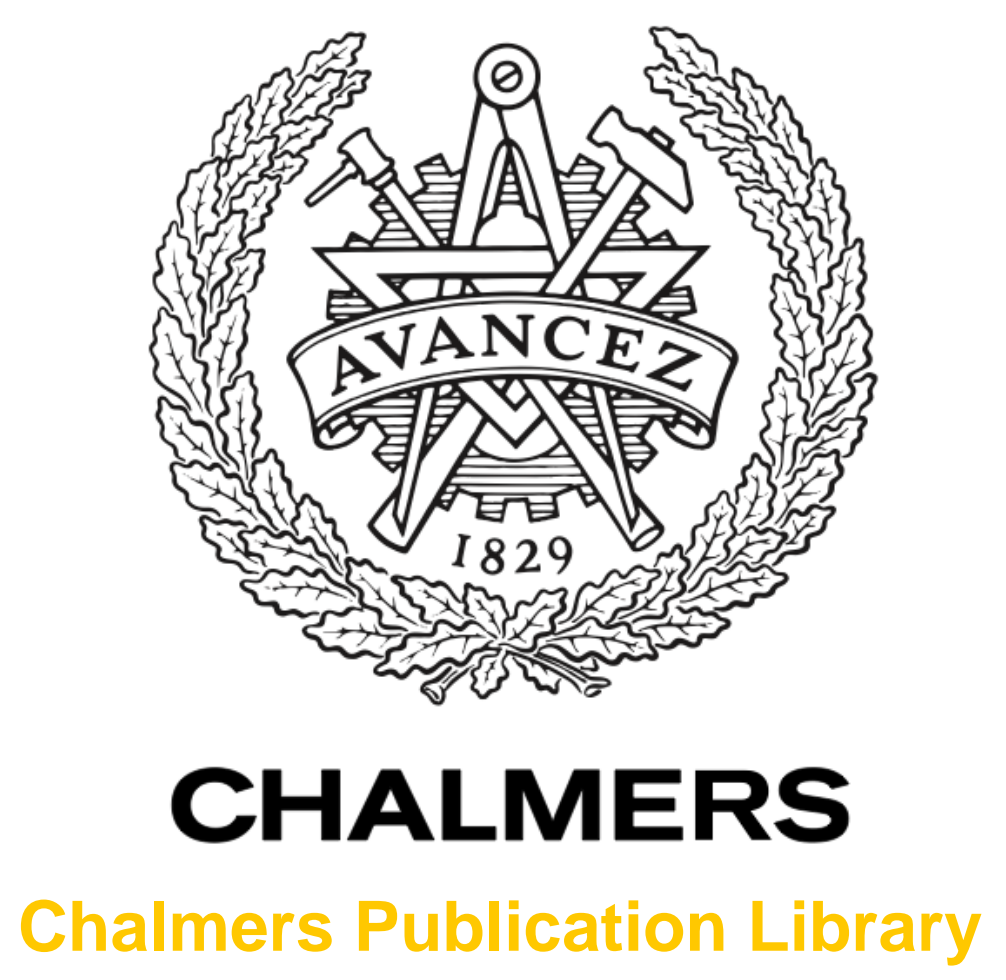

\title{
Reactor modeling assessment for urea-SNCR applications
}

This document has been downloaded from Chalmers Publication Library (CPL). It is the author's version of a work that was accepted for publication in:

International journal of numerical methods for heat \& fluid flow (ISSN: 0961-5539)

Citation for the published paper:

Finnerman, O. ; Razmjoo, N. ; Guo, N. et al. (2016) "Reactor modeling assessment for ureaSNCR applications". International journal of numerical methods for heat \& fluid flow

http://dx.doi.org/10.1108/HFF-03-2016-0135

Downloaded from: http://publications.lib.chalmers.se/publication/243471

Notice: Changes introduced as a result of publishing processes such as copy-editing and formatting may not be reflected in this document. For a definitive version of this work, please refer to the published source. Please note that access to the published version might require a subscription.

Chalmers Publication Library (CPL) offers the possibility of retrieving research publications produced at Chalmers University of Technology. It covers all types of publications: articles, dissertations, licentiate theses, masters theses, conference papers, reports etc. Since 2006 it is the official tool for Chalmers official publication statistics. To ensure that Chalmers research results are disseminated as widely as possible, an Open Access Policy has been adopted.

The CPL service is administrated and maintained by Chalmers Library. 


\title{
Reactor modeling assessment for urea-SNCR applications
}

\begin{abstract}
Purpose - The work investigates the effects of neglecting, modeling or partly resolving turbulent fluctuations of velocity, temperature and concentrations on the predicted turbulencechemistry interaction in urea-SNCR systems.

Design/methodology/approach - Numerical predictions of the NO conversion efficiency in an industrial urea-SNCR system are compared to experimental data. Reactor models of varying complexity are assessed, ranging from one-dimensional ideal reactor models to stateof-the-art CFD simulations based on the DES approach. The models employ the same reaction mechanism, but differ in the degree to which they resolve the turbulent fluctuations of the gas phase. A methodology for handling of unknown experimental data with regard to providing adequate boundary conditions is also proposed.

Findings - One-dimensional reactor models may be useful for a first quick assessment of urea-SNCR system performance. It is critical to account for heat losses, if present, due to the significant sensitivity of the overall process to temperature. The most comprehensive DES setup evaluated is associated with approximately two orders of magnitude higher computational cost than the conventional RANS-based simulations. For studies that require a large number of simulations (e.g. optimizations or handling of incomplete experimental data), the less costly approaches may be favored with a tolerable loss of accuracy.

Originality/value - Novel numerical and experimental results are presented to elucidate the role of turbulent fluctuations on the performance of a complex, turbulent, reacting multiphase flow.
\end{abstract}

Keywords Urea, Selective Non-Catalytic Reduction (SNCR), Turbulence modeling, Turbulence-chemistry interaction

Paper Type Research Paper 


\section{Introduction}

It is today well established that nitrogen oxides ( $\mathrm{NO}$ and/or $\mathrm{NO}_{2}$, collectively known as $\mathrm{NO}_{\mathrm{x}}$ ) are poisonous and contribute to acid rain and the formation of ground-level ozone (Tariq and Purvis, 1996). Industrial processes therefore have to be designed and operated so that these emissions are low enough to comply with the increasingly stricter legislation limits. Biomass combustion processes are especially prone to cause high $\mathrm{NO}_{\mathrm{x}}$ emissions, originating from the nitrogen in the fuel or the combustion air (Houshfar et al., 2012). One widely used technique to control the $\mathrm{NO}_{\mathrm{x}}$ emissions from biomass boilers is selective non-catalytic reduction (SNCR) with urea as the reducing agent. A solution of urea in water is injected into the flue gases, after which urea decomposes thermally into ammonia that may react with the $\mathrm{NO}_{\mathrm{x}}$ to produce $\mathrm{N}_{2}$ and $\mathrm{H}_{2} \mathrm{O}$. However, this process is very sensitive to temperature, exhibiting insignificant reduction and ammonia slip at low temperatures and ammonia oxidation into NO at high temperatures. The optimal temperature is dependent on the residence time, but is typically found to be around $1173 \mathrm{~K}$ (Liang et al., 2014). Given the complexity of a ureaSNCR system, with intricate interactions between the multiphase spray, chemical kinetics and the turbulent flow, detailed mathematical models represent a key in the optimization, finetuning and control of such systems. In the present work, the importance of the numerical treatment of the coupling between the turbulence and the chemical kinetics is given special consideration.

The chemistry of the urea-SNCR process is complex and involves a large number of species and reactions (Kilpinen et al., 1997; Skreiberg et al., 2004; Klippenstein, 2011). For optimizations of industrial systems, where the chemical reaction scheme has to be coupled to a description of the turbulent momentum, heat and mass transport, reduced kinetic schemes typically have to be employed. Such schemes, containing as little as two global reaction steps, exhibit good abilities to reproduce a $\mathrm{NO}_{\mathrm{x}}$ conversion behavior similar to that of the detailed mechanisms (containing hundreds of reactions) in the relevant temperature intervals (Farcy et al., 2014; Modlinski, 2015). One reason for this success of reduced kinetic schemes for the SNCR process is the fact that the process must be operated within a narrow temperature window (Brouwer et al., 1996).

Several authors have previously investigated urea-SNCR numerically. Shin et al. (2007) used simulations based on the Standard k- $\varepsilon$ model to conclude that the spray penetration depth should be large enough to obtain a high NO removal efficiency, and that good mixing of the reductant with the gas phase is critical. Liang et al. (2014) later noted that mixing is more important at temperatures higher than the optimal one.

Nguyen et al. (2009) used a seven-step global chemistry scheme (Nguyen et al., 2008) together with the Standard k- $\varepsilon$ model and the eddy-dissipation concept model (Magnussen, 1981) to simulate the NO reduction in a municipal solid-waste incinerator equipped with a urea-SNCR system. They obtained good agreement between measurements and simulations for global parameters (such as the overall NO reduction). It should be emphasized that the retention time in the system under study was quite long (>10 s). They also showed that a nonuniform droplet size distribution is beneficial to the mixing. Burström et al. (2015) also used the Standard k- $\varepsilon$ model to investigate the performance of an SNCR process for iron ore 
grate-kiln plants, where very high temperatures may be attained. They concluded that the temperature had a larger influence on the NO reduction than the residence time.

Guo et al. (2015) performed numerical investigations of a urea-spray and found that failure to resolve the turbulent velocity fluctuations of the droplet phase may have significant effects on the rate of urea thermolysis and the temperature at which it occurs. Given the importance of turbulent fluctuations on the development of the urea spray (Berlemont et al., 1995; Ström et al., 2009), also the effects of the fluctuations on the turbulence-chemistry interaction could be expected to be significant. Along these lines, Farcy et al. (2016) proposed to use a downsized numerical model to study industrial urea-SNCR systems. With this approach, well-resolved large-eddy simulations are applied to geometries that have been geometrically down-scaled by a factor of as much as 30 . This methodology is therefore primarily intended for very large systems, even by industrial standards, and Farcy et al. (2016) report using computational meshes as large as 162 million cells, to be run on high-performance computing clusters using up to 2,048 cores for a single simulation. The results of their detailed analyses indicate that the time evolution of the mean selectivity of the SNCR process is highly sensitive to the droplet topology and the level of temperature fluctuations. Whereas models for describing the dynamics of the droplet topology evolution are well established (Ström et al., 2009), the importance of temperature fluctuations on the non-linear reaction kinetics are often paid less attention. It is therefore one of the main purposes of this work to establish what gains in accuracy that can be won from a more detailed resolution of the turbulent fluctuations.

\section{Experiments}

Figure 1 presents a schematic view of the Rörvik boiler from which the experimental data was obtained. The red section in the figure delineates the part that is modelled in the numerical simulations. The urea spray comes in from the top of the horizontal segment (shown in the right panel of Figure 1). The diameter of the horizontal pipe is $1 \mathrm{~m}$ and that of the vertical pipe is $1.35 \mathrm{~m}$. The urea injector is positioned $0.57 \mathrm{~m}$ from where the horizontal pipe connects to the vertical one, which is $0.7 \mathrm{~m}$ below the top of the vertical pipe. The full length of the vertical pipe is $4.6 \mathrm{~m}$.

The gas from the boiler was extracted using a water-cooled stainless steel suction pyrometer including a type-k thermocouple at the entrance. The thermocouple was shielded from heat radiation using a ceramic socket which combined with a high suction velocity allows precise gas temperature measurements. The extracted gas was quenched in the cooled part of the suction pyrometer and then analyzed using a Fourier transform infrared (FTIR) gas spectrometer (type DX-4000; Gasmet Technologies, Helsinki, Finland). The NO concentration measurements were used as the basis for assessing the various reactor models.

\section{Modeling}

\subsection{NOx reduction chemistry}


Large reaction schemes are impractical in computational fluid dynamics (CFD) simulations, but reduced schemes have been shown to provide sufficient accuracy (Farcy et al., 2014). Here, the two-step mechanism proposed by Ostberg and Dam-Johansen (1994) is used for the NO reduction:

$\mathrm{NO}+\mathrm{NH}_{3}+1 / 4 \mathrm{O}_{2} \rightarrow \mathrm{N}_{2}+3 / 2 \mathrm{H}_{2} \mathrm{O}$

$\mathrm{NH}_{3}+5 / 4 \mathrm{O}_{2} \rightarrow \mathrm{NO}+3 / 2 \mathrm{H}_{2} \mathrm{O}$

The Arrhenius rate expressions for these reactions are given in Table 1.

\subsection{One-dimensional reactor models}

One-dimensional reactor models are the most simplistic mathematical descriptions of industrial reactors. Because of their simplicity, they enable efficient handling of large reaction mechanisms. At the same time, it is widely agreed that complex, turbulent reactive multiphase flows cannot be well described by one-dimensional reactor models (Sundaresan, 2000; Ekambara et al., 2005). For such systems, CFD models of coupled non-linear partial differential equations typically have to be solved. In the current work, the performance of two common isothermal one-dimensional reactor models are used to contrast the numerical predictions obtained from the comprehensive CFD simulations.

\subsubsection{Continuous stirred-tank reactor (CSTR) model}

The CSTR model assumes perfect mixing, which leads to a species mass balance on the following form:

$$
C_{i, \text { in }}-C_{i, \text { out }}+\tau \sum_{n=1}^{N_{R S}} \alpha_{i, n} r_{n}=0
$$

\subsubsection{Plug flow reactor (PFR) model}

The PFR model assumes non-dispersive one-dimensional transport and reaction, which leads to a species mass balance on the following form:

$$
\frac{d C_{i}}{d \tau}=\sum_{n=1}^{N_{R S}} \alpha_{i, n} r_{n}
$$

The concentrations at the reactor outlet are obtained by integrating this ordinary differential equation in time.

\subsection{Three-dimensional reactor models}


In the comprehensive reactor models, the water evaporation and urea thermolysis in the spray are also included. The heat and mass transfer and chemical reactions of this process are modelled according to the scheme proposed by Lundström et al. (2011), implying that the urea thermolysis is modelled as an evaporation process. The motion of the droplets in the gas is described within an Eulerian-Lagrangian framework, accounting for momentum transfer via drag and turbulent dispersion via an eddy-interaction model, as in the setup used by Ström et al. (2009). The complete spray model predicts the trajectories of the droplets and the evolution of their masses and temperatures. The exchange of heat, mass and momentum with the gas phase is accounted for via source terms in the gas balance equations. As the droplets in the spray are small in relation to the largest turbulent eddies, it is assumed that the local effect of the presence of the spray on the turbulent quantities can be neglected. The main purpose of the detailed spray model is thus to produce realistic conditions (temperature and concentrations) for the $\mathrm{NO}_{\mathrm{x}}$ reduction chemistry in the gas phase. More details on the implementation used can be found in Ström and Lundström (2011). The inlet flow rate of the urea solution was taken from the experimental data. The spray setup was not air-assisted.

The gas-phase decomposition of urea is described by the two-step mechanism proposed by Rota et al. (2002):

$$
\begin{gathered}
\mathrm{NH}_{2}-\mathrm{CO}-\mathrm{NH}_{2} \rightarrow \mathrm{HNCO}+\mathrm{NH}_{3} \\
\mathrm{HNCO}+\mathrm{H}_{2} \mathrm{O} \rightarrow \mathrm{NH}_{3}+\mathrm{CO}_{2}
\end{gathered}
$$

The rates of the homogeneous chemical reactions (I-IV) are calculated using the harmonic mean of the two rates obtained from the turbulence-chemistry interaction model of Magnussen and Hjertager (1976) and the corresponding global Arrhenius expression, respectively. The only exception is the urea decomposition reaction (III), which is a unimolecular reaction that cannot be limited by mixing, implying that the Arrhenius expression is always used. In the turbulence-chemistry interaction model, the net rate of production of a species, if limited by the large-eddy mixing rate, is obtained via the mixing time scale associated with the largest unresolved eddies. As more of the turbulence is resolved and less is modelled, the time scale associated with the unresolved part of the turbulence will decrease, theoretically approaching a point where all turbulence is resolved and the turbulent mixing can no longer limit the reaction rate. The Arrhenius rate expressions to be used in the turbulence-chemistry interaction model are obtained as shown in Table 1. Finally, it should also be stressed here that it is not in general possible to use the herein employed turbulencechemistry interaction model with larger reaction mechanisms when turbulent mixing is the limiting process, as individual reaction rates become indistinguishable (Jones et al., 2014). This fact, along with the previous success of two-step reaction mechanisms for the SNCR process, provides the main motivation for not employing one of the more detailed reaction mechanisms available in the literature.

The Mach number is significantly smaller than 0.3 , so that the fluid flow field may be obtained by solving the incompressible Reynolds-Averaged Navier-Stokes (RANS) equations: 


$$
\begin{gathered}
\frac{\partial \bar{u}_{l}}{\partial x_{i}}=S_{M S} \\
\frac{\partial \bar{u}_{l}}{\partial t}+\bar{u}_{\jmath} \frac{\partial \bar{u}_{\imath}}{\partial x_{j}}=-\frac{1}{\rho} \frac{\partial p}{\partial x_{i}}+v\left(\frac{\partial \bar{u}_{l}}{\partial x_{j}}+\frac{\partial \bar{u}_{J}}{\partial x_{i}}\right)+\frac{\partial}{\partial x_{j}}\left(-\overline{u_{\imath}^{\prime} u_{\jmath}^{\prime}}\right)+S_{M}
\end{gathered}
$$

The third term on the right hand side of the momentum balance represents the Reynolds stresses, which need to be modelled. In this work, the Boussinesq approach is used, in which an analogy with the viscous stresses is used to introduce a turbulent viscosity, $v_{t}$ :

$$
-\overline{u_{\imath}^{\prime} u_{\jmath}^{\prime}}=v_{t}\left(\frac{\partial \overline{u_{\imath}}}{\partial x_{j}}+\frac{\partial \overline{u_{\jmath}}}{\partial x_{i}}\right)-\frac{2}{3} k \delta_{i j}
$$

The differences between the various turbulence models evaluated in the current work lie in how the turbulent viscosity is determined.

\subsubsection{Standard $k-\varepsilon$ model}

With the Standard $\mathrm{k}-\varepsilon$ model, the turbulent viscosity is obtained from the turbulent kinetic energy $(k)$ and the turbulent energy dissipation rate $(\varepsilon)$ :

$$
v_{t}=C_{\mu} \frac{k^{2}}{\varepsilon}
$$

The local values of $k$ and $\varepsilon$ are obtained by solving two additional transport equations for these entities:

$$
\begin{gathered}
\frac{\partial k}{\partial t}+\frac{\partial}{\partial x_{i}}\left(k \overline{u_{l}}\right)=\frac{\partial}{\partial x_{j}}\left[\left(v+\frac{v_{t}}{\sigma_{k}}\right) \frac{\partial k}{\partial x_{j}}\right]+2 v_{t} S_{i j} S_{i j}-\varepsilon \\
\frac{\partial \varepsilon}{\partial t}+\frac{\partial}{\partial x_{i}}\left(\varepsilon \overline{u_{l}}\right)=\frac{\partial}{\partial x_{j}}\left[\left(v+\frac{v_{t}}{\sigma_{\varepsilon}}\right) \frac{\partial \varepsilon}{\partial x_{j}}\right]+2 v_{t} C_{1 \varepsilon} \frac{\varepsilon}{k} S_{i j} S_{i j}-C_{2 \varepsilon} \frac{\varepsilon^{2}}{k}
\end{gathered}
$$

\subsubsection{SST k-w model}

With the shear-stress transport (SST) k- $\omega$ model, the turbulent viscosity is obtained using:

$$
v_{t}=\frac{k}{\omega} \frac{1}{\max \left[\frac{1}{\alpha^{*}}, \frac{S F_{2}}{a_{1} \omega}\right]}
$$

The local values of $k$ and $\omega$ are obtained by solving two additional transport equations for these entities (Menter, 1994): 


$$
\begin{gathered}
\frac{\partial k}{\partial t}+\frac{\partial}{\partial x_{i}}\left(k \bar{u}_{\imath}\right)=\frac{\partial}{\partial x_{j}}\left[\left(v+\frac{v_{t}}{\sigma_{k f}}\right) \frac{\partial k}{\partial x_{j}}\right]+2 v_{t} S_{i j} S_{i j}-\beta^{*} f_{\beta^{*}} k \omega \\
\frac{\partial \omega}{\partial t}+\frac{\partial}{\partial x_{i}}\left(\omega \bar{u}_{\imath}\right)=\frac{\partial}{\partial x_{j}}\left[\left(v+\frac{v_{t}}{\sigma_{\omega f}}\right) \frac{\partial \omega}{\partial x_{j}}\right]+2 \alpha \alpha^{*} S_{i j} S_{i j}-\beta f_{\beta} \omega^{2}+2\left(1-F_{1}\right) \frac{1}{\omega \sigma_{\omega, 2}} \frac{\partial k}{\partial x_{j}} \frac{\partial \omega}{\partial x_{j}}
\end{gathered}
$$

\subsubsection{SST $k-\omega D E S$}

The essence of the idea behind the detached-eddy simulation technique is to allow the turbulent viscosity to vary also with the mesh resolution. In regions of low resolution, most of the turbulent fluctuations will be modelled and the DES method will essentially revert to a standard SST k- $\omega$ model. In regions of fine mesh resolution, turbulent fluctuations will be resolved to some extent, and the modelled part will be smaller. Consequently, the turbulent viscosity in regions of fine mesh resolution should decrease. In the SST k- $\omega$ DES model, the last source term in the transport equation for $k$ is altered to obtain a dependency on the local mesh resolution, $\Delta$ :

$$
\frac{\partial k}{\partial t}+\frac{\partial}{\partial x_{i}}\left(k \bar{u}_{\imath}\right)=\frac{\partial}{\partial x_{j}}\left[\left(v+\frac{v_{t}}{\sigma_{k}}\right) \frac{\partial k}{\partial x_{j}}\right]+2 v_{t} S_{i j} S_{i j}-\beta^{*} k \omega F_{D E S}
$$

where

$$
F_{D E S}=\max \left[\frac{L_{t}}{C_{d e s} \Delta_{\max }}\left(1-F_{S S T}\right), 1\right]
$$

In this work, the detached-eddy simulations are performed on refined versions of the meshes used for the Standard k- $\varepsilon$ and SST k- $\omega$ models. The resolution in the DES therefore ranges from identical to that of the other models (in the near-wall regions) to significantly finer (in the core of the duct). In the regions of finer resolution, the turbulent viscosity is decreased in the DES due to the increased dissipation of turbulent energy outlined above, which allows turbulent structures to be resolved and propagated without artificial dampening by the underlying turbulence model (Forrest and Owen, 2010). Consequently, there is no fixed interface between regions of different level of resolution, and the actual ratio of resolved to modelled turbulent energy becomes mesh-dependent, just like in a large-eddy simulation (LES) when the mesh is the filter (Sagaut, 1998). With this DES implementation, the same model equations are thus solved throughout the entire computational domain.

\subsubsection{Heat and mass balances}

The heat and mass balances are identical for all turbulence treatments. They use the resolved velocity field and models the effect of sub-grid fluctuations with a turbulent thermal conductivity and a turbulent mass diffusivity, respectively. In effect, the temperature and concentrations are therefore treated with a similar resolution as the velocity field: 


$$
\begin{gathered}
\frac{\partial E}{\partial t}+\frac{\partial}{\partial x_{i}}\left[\bar{u}_{\imath}\left(E+\frac{p}{\rho}\right)\right]=\frac{\partial}{\partial x_{j}}\left\{\left(k_{t}+k_{t, t}\right) \frac{\partial T}{\partial x_{j}}+\sum_{n} h_{n}\left[\left(D_{n}+\frac{v_{t}}{\rho S c_{t}}\right) \frac{\partial Y_{n}}{\partial x_{j}}\right]\right\}+S_{H} \\
\frac{\partial Y_{i}}{\partial t}+\frac{\partial}{\partial x_{i}}\left(\bar{u}_{\imath} Y_{i}\right)=\frac{\partial}{\partial x_{j}}\left[\left(D_{i}+\frac{v_{t}}{\rho S c_{t}}\right) \frac{\partial Y_{i}}{\partial x_{j}}\right]+\frac{1}{\rho}\left(R_{i}+S_{i, M S}\right)
\end{gathered}
$$

\subsection{Initial and boundary conditions}

A full overview over the CFD cases investigated in the current work is provided in Table 4.

The computational domain is constituted of two connected pipes, forming a duct with a $90^{\circ}$ bend and dead volume at the top (cf. Figure 1). In the DES cases, the inlet boundary conditions for velocity are synthesized according to the method of Smirnov et al. (2001). The horizontal pipe is therefore elongated so that the inlet is placed five duct diameters upstream the urea injector, for the flow field to adjust from the inlet boundary. The same domain is used for all simulations. Initial conditions for the DES cases are obtained by superimposing fluctuations onto Standard k- $\varepsilon$ solutions. The DES cases are then advanced in time for a few domain flow-through times before the sampling of statistics is commenced. The sampling then continues until the statistics reach a steady state.

Two experimental data sets from the Rörvik boiler were chosen for the comparisons. Incomplete experimental data sets represent an unfortunate nuisance that must be handled in studies related to real-world large-scale plant operation. For this particular study, no measurement data was available for the horizontal inlet pipe. It is therefore assumed that the horizontal section of the computational domain is adiabatic, and that the temperature and species concentrations at the inlet are the same as the measured ones at $h=1 \mathrm{~m}$ when the urea injection was turned off. The measured inlet NO concentrations are then in the range 60-95 ppm for the data used in the current work.

Furthermore, there are significant heat losses from the duct, as identified from an observed temperature drop in the streamwise direction during the measurements. An external heat transfer coefficient was therefore fitted in the high-temperature Standard k- $\varepsilon$ simulation to ensure that the temperature obtained at $h=3 \mathrm{~m}$ matched that of the experimental measurement when the urea spray was turned off. In addition, there was no temperature measurement available at $h=1 \mathrm{~m}$ for the low-temperature operating point. Therefore, it was assumed that the external heat transfer coefficient was the same for both operating points (a reasonable assumption), in which case the inlet temperature was chosen to reproduce the experimentally measured temperature at $h=3 \mathrm{~m}$, with the urea spray turned off, in the Standard k- $\varepsilon$ simulation. The inlet temperatures for the low and high temperature cases were finally obtained as $1115 \mathrm{~K}$ and $1239 \mathrm{~K}$, respectively, and the heat transfer coefficient was 4.9 $\mathrm{W} / \mathrm{m}^{2}, \mathrm{~K}$. To evaluate the effect of taking the heat losses into account, simulations are also performed with the Standard k- $\varepsilon$ model for a fully adiabatic system. To allow for a more indepth comparison of the different model predictions, a "very low" temperature of $1050 \mathrm{~K}$ and 
a "very high" temperature of $1300 \mathrm{~K}$ were added for the simulations, along with a medium temperature of $1177 \mathrm{~K}$.

In all simulations, the walls have standard wall functions for the fluid flow and the outlet boundary condition is a pressure-outlet.

\subsection{Numerical details}

The system of partial differential equations is discretized on a co-located grid and solved by the segregated pressure-based Navier-Stokes solver in ANSYS Fluent 16.0. The temporal discretization is done with a second-order accurate implicit scheme. Convective terms in all balance equations (except the one for momentum in the detached-eddy simulations) are discretized using a second-order upwind scheme, and the diffusion terms are discretized using a second-order central-differencing scheme. The convective terms in the momentum balance equations for the detached-eddy simulations are discretized using an unbounded second-order central differencing scheme, in order not to numerically dampen out the resolved turbulence. The pressure-velocity coupling used is SIMPLE, and a second-order central-differencing scheme is used to interpolate the pressure values at the faces. The time step is chosen to obtain a Courant number below unity to allow the fluid-droplet coupling to be fully and robustly accounted for. At this fine temporal resolution, the solution is independent of the time step chosen. The droplet tracking is performed with a second-order accurate implicit trapezoidal scheme.

The computational mesh used for the RANS cases is made out of tetrahedral cells with an orthogonal quality of 0.80 on average and a minimum of 0.24 . Here, the orthogonal quality is defined as the minimum of the normalized dot product of the area vector of a face and a vector from the centroid of the cell to either the centroid of that face or the centroid of the adjacent cell that shares the face in question. The maximum cell skewness in the mesh is 0.72 , and the average is 0.20 . For the finer meshes used for the DES cases, the orthogonal quality is 0.75 on average and 0.085 at minimum, whereas the skewness is 0.21 on average and 0.86 at maximum. All these values imply that the mesh quality is satisfactory and that no issues with poor convergence or low accuracy are to be expected. The mesh resolution in the vicinity of the urea injector lies in the range $7.8-15 \mathrm{~mm}$.

\section{Results and Discussion}

\subsection{Grid refinement study}

The simulations are performed on three different grids, the sizes of which are reported in Table 2. The DES results from the two finer grids are in very good agreement, confirming that the medium grid can be trusted as accurate for the results needed for the present work. The difference in the calculated NO level in the measurement point was smaller than $1 \%$ for these two grids. 


\subsection{Turbulence resolution and computational efficiency}

The ratio of resolved to modelled turbulence in the different computational cases can be appreciated from the data in Table 2. In the non-DES cases, all turbulence is modelled and there is no direct relation between the cell spacing and the large eddy length scale predicted by the respective turbulence models. When DES is employed and the cell spacing is decreased, the unresolved turbulence is characterized by increasingly smaller spatial scales, and the ratio of the turbulent viscosity to the molecular viscosity decreases significantly. It should specifically be noted that on the finest grid employed, the largest turbulent structures present are approximately 25 times larger than the cell spacing. Consequently, the turbulent viscosity is of similar order of magnitude as the molecular viscosity for this case. These detached-eddy simulations are therefore of similar resolution to the large-eddy simulations performed by Farcy et al. (2016).

The number of cells in the DES grid is more than 30 times larger than that of the conventional RANS simulations. In addition, the results must be time-averaged to obtain the statistically steady-state result. In conclusion, the computational cost of performing a detached-eddy simulation is approximately two orders of magnitude larger than that of performing a standard RANS simulation.

\subsection{NO conversion}

The NO conversion in the measurement point at the height location $h=3 \mathrm{~m}$ (cf. Figure 1 ) is used as a basis for comparing the different model predictions. The numerical results are compared in Figure 2, where the NO conversion is plotted against the inlet temperature to the computational domain. For a fair comparison between the isothermal cases and the cases with heat losses, it should therefore be stressed that the inlet temperature represents the maximum temperature, and that the actual temperature in the region where the reactions take place is lower. It should also be noted that the data point for the Standard k- $\varepsilon$ case at an inlet temperature of $1300 \mathrm{~K}$ is not shown in the figure, since at this temperature the $\mathrm{NH}_{3}$ oxidation reaction causes an increase in the NO concentration out (cf. Table 3).

A number of interesting inferences can be made from the comparison in Figure 2. First of all, the optimum temperature obtained with the current two-step reaction kinetics in the onedimensional reactor models is approximately $1190 \mathrm{~K}$, which is in good agreement with literature data (von der Heide, 2008; Liang et al., 2014). This observation implies that this reaction mechanism can be used to produce reasonable predictions in the CFD simulations. Although the CSTR model is seemingly in good agreement with the experimental data at the low-temperature operating point, this level of agreement is most probably a consequence of chance. The CSTR model assumes perfect mixing and uniform temperature, and so cannot be expected to reproduce the intricate coupling of these processes in the real-world application (Nguyen et al., 2009). The CSTR model does however seem to be a better approximation than the PFR model for the current system. The spray in the CFD simulations reaches into the central section of the duct, in line with the recommendations of Shin et al. (2007) for an efficient NO removal, and the non-adiabatic CFD simulations consistently produces NO 
conversion estimates close to, but somewhat lower than, the CSTR predictions, except around the optimum temperature.

Next, it can be seen that the adiabatic Standard k- $\varepsilon$ cases overpredict the NO conversion at the lower temperature and underpredict it at the higher temperature. These observations confirm that heat losses, if present, have a significant effect on the NO conversion and must be accounted for. Adiabatic models will use a too high temperature, thus always underpredicting the NO conversion above the optimum temperature and overpredicting it below.

Furthermore, the CFD simulations with heat losses (both Standard k- $\varepsilon$ and SST k- $\omega$ DES) are relatively similar. Both cases underpredict the NO conversion at the lower operating temperature and overpredict it at the higher operating temperature, in relation to the experimental data. As shown in Figure 3, the NO concentration fields from these simulations exhibit significant gradients near the measuring point at $h=3 \mathrm{~m}$. A minor deviation of the measuring lance from the duct center in the experiments would therefore have a significant effect on the outcome of the comparison.

For this reason, the point in the plane at $h=3 \mathrm{~m}$ in which the best possible agreement between the numerical simulations and the measurements could be found was also identified. This point turned out to be a mere $30 \mathrm{~cm}$ to the left of the duct center, which corresponds to an angle of the measuring lance of only $4^{\circ}$. For such a small inclination, the agreement is indeed very good, as can be seen in Figure 4. The only outlier is the SST k- $\omega$ DES at the high temperature, which exhibits a larger deviation to the experimental value in this alternate measurement location. The reason can be hinted in Figure 3 - in the high-temperature DES, the regions of maximum NO reduction are not found in the duct center, but in the two streaks formed by the two rotational centers in the bending pipe (cf. Ström et al., 2010; Röhrig et al., 2015). It is therefore also possible to find an alternate measurement point that would make the high-temperature SST k- $\omega$ DES agree with the experimental data, but that point is offset a bit from the duct centerplane and does not coincide with the point that produces the best fit for the three other computational cases. In conclusion, all numerical solutions produce NO concentrations in the plane at $h=3 \mathrm{~m}$ that may agree with the experimentally determined NO concentration, albeit not exactly at the duct center.

\subsection{Reactor model assessment}

The chosen set of computational cases also allows for an investigation where the DES results are compared to the results obtained with the standard versions of the two turbulence models on the coarsest mesh. This detailed comparison is carried out for the high-temperature case only, as the role of mixing is known to be more significant above the optimum temperature (Liang et al., 2014). A comparison is made in Figure 5, where the mass-averaged $\mathrm{NO}_{\mathrm{x}}$ conversion over the duct cross-section at different heights is plotted as a function of the size of the computational grid for the high-temperature case. The results obtained with the Standard k- $\varepsilon$ and the SST k- $\omega$ model on the smallest mesh are in fair agreement, with the k- $\omega$ prediction seemingly exhibiting a higher selectivity towards NO oxidation. The differences observed when switching to a detached-eddy version of the SST k- $\omega$ model on a finer grid are 
significant. These results also illustrate the pronounced sensitivity of the NO conversion to the point or plane in space where the data is collected, as the NO conversion at $h=1,2$ and $3 \mathrm{~m}$ vary significantly. It should therefore be stressed that the NO conversion at $1 \mathrm{~m}$ above the domain outlet in all simulations is positive and of similar magnitude (cf. Table 3). This observation might explain the good agreement found previously for long residence times (Nguyen et al., 2009; Modlinski, 2015). It should also be stressed that the trends for the NO conversion in the sample point are identical for the Standard k- $\varepsilon$ and DES cases, as seen from Figure 2. Finally, it is also important to realize that the heat losses, which were shown to have a large effect on the predicted results, were fitted with the Standard k- $\varepsilon$ model on the coarse mesh, and hence may not be optimal for the DES.

\section{Conclusions}

Reactor models of varying complexity have been assessed for numerical predictions of the NO conversion in a urea-SNCR system attached to an industrial biomass boiler. It is shown that although simplistic one-dimensional reactor models cannot be used to support the detailed design of real-world units, they do produce useful (over-)estimations of the NO conversion at a given temperature and residence time. Due to the significant dependence of the SNCR chemistry on temperature, heat losses must be accounted for in more comprehensive reactor models. Detached-eddy simulations provide the means to carry out investigations where the effects of turbulent fluctuations on heat and mass transfer and chemical kinetics can be resolved to some extent for industrial-sized cases. The present comparison between experimental and numerical results does however not support the conclusion that DES is superior to conventional RANS-based turbulence modeling for optimization studies, due to the significant additional computational cost of performing DES for parametric variations. Finally, cases involving incomplete experimental data on boundary conditions are also less suitable for a comprehensive DES treatment, as these cases typically require an iterative simulation procedure to enable the derivation of reasonable boundary condition settings.

\section{Acknowledgements}

This work is a significantly extended version of a material first presented at the $10^{\text {th }}$ International Symposium on Numerical Analysis of Fluid Flow and Heat Transfer (Numerical Fluids 2015) on September 23-29, 2015 in Rhodes, Greece.

\section{References}

Berlemont, A., Grancher, M. S., Gouesbet, G., Heat and mass transfer coupling between vaporizing droplets and turbulence using a lagrangian approach, International Journal of Heat and Mass Transfer 38 (1995) 3023-3034.

Brouwer, J., Heap, M. P., Pershing, D. W., Smith, P. J., A model for prediction of selective noncatalytic reduction of nitrogen oxides by ammonia, urea, and cyanuric acid with mixing limitations 
in the presence of CO, Twenty-Sixth Symposium (International) on Combustion/The Combustion Institute (1996) 2117-2124.

Burström, P. E. C., Antos, D., Lundström, T. S., Marjavaara, B. D., A CFD-based evaluation of selective non-catalytic reduction of nitric oxide in iron ore grate-kiln plants, Progress in Computational Fluids Dynamics 15 (2015) 32-46.

Ekambara, K., Dhotre, M. T., Joshi, J. B., CFD simulations of bubble column reactors: 1D, 2D and 3D approach, Chemical Engineering Science 60 (2005) 6733-6746.

Farcy, B., Abou-Taouk, A., Vervisch, L., Domingo, P., Perret, N., Two approaches of chemistry downsizing for simulating selective non catalytic reduction DeNOx process, Fuel 118 (2014) 291-299.

Farcy, B., Vervisch, L., Domingo, P., Large eddy simulation of selective non-catalytic reduction (SNCR): a downsizing procedure for simulating nitric-oxide reduction units, Chemical Engineering Science 139 (2016) 285-303.

Forrest, J. S., Owen, I., An investigation of ship airwakes using detached-eddy simulation, Computers \& Fluids 39 (2010) 656-673.

Guo, N., Finnerman, O., Ström, H., The effect of turbulent velocity fluctuations on the convective heat and mass transfer to droplets subjected to evaporation and thermolysis, AIP Conference Proceedings (Accepted) 2015.

Houshfar, E., Skreiberg, $\varnothing$., Todorovic, D., Skreiberg, A., Lövås, T., Jovovic, A., Sörum, L., NOx emission reduction by staged biomass combustion in grate combustion of biomass fuels and fuel mixtures, Fuel 98 (2012) 29-40.

Jones, J. M., Lea-Langton, A. R., Ma, L., Pourkashanian, M., Williams, A., Pollutants generated by the combustion of solid biomass fuels, Springer, London, ISBN 978-1-4471-6436-4, 2014.

Kilpinen, P., Hupa, M., Aho, M., Selective non-catalytic NOx reduction at elevated pressures: studies on the risk of increased $\mathrm{N} 2 \mathrm{O}$ emissions, $7^{\text {th }}$ International Workshop on Nitrous Oxide Emissions, Cologne, Germany, 1997.

Klippenstein, S. J., Harding, L. B., Glarborg, P., Miller, J. A., The role of NNH in NO formation and control, Combustion and Flame 158 (2011) 774-789.

Liang, L., Hui, S., Pan, S., Shang, T., Liu, C., Wang, D., Influence of mixing, oxygen and residence time on the SNCR process, Fuel 120 (2014) 38-45.

Lundström, A., Ström, H., Modeling aspects of the injection of urea-spray for $\mathrm{NO}_{\mathrm{x}}$ abatement for heavy duty diesel engines, in: Sprays: Types, Technology and Modeling (ed. Maria C. Vella), Nova Science Publishers, Inc., Hauppauge, ISBN 978-1-61324-345-9, 2011.

Lundström, A., Waldheim, B., Ström, H., Westerberg, B., Modelling of urea gas phase thermolysis and theoretical details on urea evaporation, Proceedings of the Institution of Mechanical Engineers, Part D: Journal of Automobile Engineering 225 (2011) 1392-1398.

Magnussen, B. F., On the Structure of Turbulence and a Generalized Eddy Dissipation Concept for Chemical Reaction in Turbulent Flow, Nineteenth AIAA Meeting, St. Louis, USA, 1981.

Magnussen, B. F., Hjertager, B. H., On mathematical models of turbulent combustion with special emphasis on soot formation and combustion, $16^{\text {th }}$ Symposium (Int'l) on Combustion, The Combustion Institute, 1976.

Menter, F. R., Two-equation eddy-viscosity turbulence models for engineering applications, AIAA Journal 32 (1994) 1598-1605. 
Modlinski, N., Numerical simulation of SNCR (selective non-catalytic reduction) process in coal fired grate boiler, Energy 92 (2015) 67-76.

Nguyen, T. D. B., Lim, Y.-I., Kim, S.-J., Eom, W.-H., Yoo, K.-S., Experiment and computational fluid dynamics (CFD) simulation of urea-based selective noncatalytic reduction (SNCR) in a pilot-scale flow reactor, Energy \& Fuels 22 (2008) 3864-3876.

Nguyen, T. D. B., Kang, T.-H., Lim, Y.-I., Eom, W.-H., Kim, S.-J., Yoo, K.-S., Application of ureabased SNCR to a municipal incinerator: on-site test and CFD simulation, Chemical Engineering Journal 152 (2009) 36-43.

Ostberg, M., Dam-Johansen, K., Empirical modeling of the selective non-catalytic reduction of NO: comparison with large-scale experiments and detailed kinetic modeling, Chemical Engineering Science 49 (1994) 1897-1904.

Rota, R., Antos, D., Zanoelo, E. F., Morbidelli, M., Experimental and modeling analysis of the NOxOUT process, Chemical Engineering Science 57 (2002) 27-38.

Röhrig, R., Jakirlic, S., Tropea, C., Comparative computational study of turbulent flow in a $90^{\circ}$ pipe elbow, International Journal of Heat and Fluid Flow 55 (2015) 120-131.

Sagaut, P., Large eddy simulation for incompressible flows, Springer, Berlin, ISBN 978-3-540-263449, 1998.

Shin, M.-S., Kim, H.-S., Jang, D.-S., Numerical study on the SNCR application of space-limited industrial boiler, Applied Thermal Engineering 27 (2007) 2850-2857.

Skreiberg, O., Kilpinen, P., Glarborg, P., Ammonia chemistry below 1400K under fuel-rich conditions in a flow reactor, Combustion and Flame 136 (2004) 501-518.

Smirnov, R., Shi, S., Celik, I., Random flow generation technique for large eddy simulations and particle-dynamics modeling, Journal of Fluids Engineering 123 (2001) 359-371.

Ström, H., Lundström, A., Andersson, B., Choice of urea-spray models in CFD simulations of ureaSCR systems, Chemical Engineering Journal 150 (2009) 69-82.

Ström, H., Sasic, S., Andersson, B., Design of automotive flow-through catalysts with optimized soot trapping capability, Chemical Engineering Journal 165 (2010) 934-945.

Sundaresan, S., Modeling the hydrodynamics of multiphase flow reactors: current status and challenges, AIChE Journal 46 (2000) 1102-1105.

Tariq, A. S., Purvis, M. R. I., NOx emissions and thermal efficiencies of small scale biomass-fuelled combustion plant with reference to process industries in a developing country, International Journal of Energy Research 20 (1996) 41-55.

von der Heide, B., SNCR Process - Best available technology for NOx reduction in waste to energy plants, POWER-GEN Europe, 3-5 June, Milan, Italy, 2008. 


\section{Tables}

\begin{tabular}{|l|c|l|l|}
\hline Reaction & Rate expression & Arrhenius parameters & Reference \\
\hline I & $r=A T^{b} \exp \left[-E_{a} / R T\right] C_{N O} C_{N H 3}$ & $\begin{array}{l}A=4.24 \cdot 10^{2} \mathrm{~m}^{3} / \mathrm{mol}, \mathrm{s}, \mathrm{K}^{5.3} \\
b=5.30 \\
E_{a}=349,937 \mathrm{~J} / \mathrm{mol}\end{array}$ & $\begin{array}{l}\text { Ostberg } \\
\text { and Dam- } \\
\text { Johansen } \\
(1994)\end{array}$ \\
\hline II & $r=A T^{b} \exp \left[-E_{a} / R T\right] C_{N H 3} C_{O 2}$ & $\begin{array}{l}A=3.50 \cdot 10^{-1} \mathrm{~m}^{3} / \mathrm{mol}, \mathrm{s}, \mathrm{K}^{7.65} \\
b=7.65 \\
E_{a}=524,487 \mathrm{~J} / \mathrm{mol}\end{array}$ & $\begin{array}{l}\text { Ostberg } \\
\text { and Dam- } \\
\text { Johansen } \\
(1994)\end{array}$ \\
\hline III & $r=A \exp \left[-E_{a} / R T\right] C_{N H 2-C O-N H 2}$ & $\begin{array}{l}A=1.27 \cdot 10^{4} \mathrm{~s}^{-1} \\
E_{a}=65,048 \mathrm{~J} / \mathrm{mol}\end{array}$ & $\begin{array}{l}\text { Rota et al. } \\
(2002)\end{array}$ \\
\hline IV & $r=A \exp \left[-E_{a} / R T\right] C_{H N C O} C_{H 2 O}$ & $\begin{array}{l}A=6.13 \cdot 10^{4} \mathrm{~m}^{3} / \mathrm{mol}, \mathrm{s} \\
E_{a}=87,819 \mathrm{~J} / \mathrm{mol}\end{array}$ & $\begin{array}{l}\text { Rota et al. } \\
(2002)\end{array}$ \\
\hline
\end{tabular}

Table 1. Arrhenius rate expressions for the homogeneous chemical reactions. 


\begin{tabular}{|l|c|c|c|c|}
\hline Computational case & $\begin{array}{c}\text { Total } \\
\text { number of } \\
\text { cells }\end{array}$ & $\begin{array}{c}\text { Typical cell } \\
\text { spacing }\end{array}$ & $\begin{array}{c}\text { Typical length } \\
\text { scale of large } \\
\text { unresolved } \\
\text { turbulent eddies }\end{array}$ & $\begin{array}{c}\text { Mass-averaged / } \\
\text { maximum ratio } \\
\text { of turbulent to } \\
\text { molecular } \\
\text { viscosities }\end{array}$ \\
\hline Standard k- $\varepsilon$ & 74,709 & $5 \mathrm{~cm}$ & $10 \mathrm{~cm}$ & $145 / 496$ \\
\hline SST k- $\omega$ & 74,709 & $5 \mathrm{~cm}$ & $10 \mathrm{~cm}$ & $70 / 267$ \\
\hline SST k- $\omega$ DES & $2,409,657$ & $8 \mathrm{~mm}$ & $2.5 \mathrm{~mm}$ & $10 / 63$ \\
\hline SST k- $\omega$ DES refined & $22,020,477$ & $4 \mathrm{~mm}$ & $1 \mathrm{~mm}$ & $4 / 46$ \\
\hline
\end{tabular}

Table 2. Mesh characteristics and turbulence resolution for the different high-temperature cases. The typical length scale of the large unresolved turbulent eddies is obtained as $C_{\mu}{ }^{3 / 4} k^{3 / 2} / \varepsilon$. The typical length scale and typical cell spacing refer to the core of the flow where the reactions take place. 


\begin{tabular}{|l|l|l|l|}
\hline Turbulence model & Temperature case & Inlet temperature & $\begin{array}{l}\text { Average NO } \\
\text { conversion }\end{array}$ \\
\hline Standard k- $\varepsilon$ & Very low & $1050 \mathrm{~K}$ & $5.5 \%$ \\
\hline SST k- $\omega$ DES & Low & $1115 \mathrm{~K}$ & $35 \%$ \\
\hline Standard k- $\varepsilon$ & Low & $1115 \mathrm{~K}$ & $46 \%$ \\
\hline SST k- $\omega$ DES & Medium & $1177 \mathrm{~K}$ & $55 \%$ \\
\hline Standard k- $\varepsilon$ & Medium & $1177 \mathrm{~K}$ & $72 \%$ \\
\hline SST k- $\omega$ DES & High & $1239 \mathrm{~K}$ & $53 \%$ \\
\hline Standard k- $\varepsilon$ & High & $1239 \mathrm{~K}$ & $47 \%$ \\
\hline Standard k- $\varepsilon$ & Very high & $1300 \mathrm{~K}$ & $-276 \%$ \\
\hline
\end{tabular}

Table 3. Mass-averaged NO conversions $1 \mathrm{~m}$ before the domain outlet for the various temperature cases with SST k- $\omega$ DES and Standard k- $\varepsilon$. 


\begin{tabular}{|l|l|l|l|l|}
\hline $\begin{array}{l}\text { Operating } \\
\text { temperature }\end{array}$ & $\begin{array}{l}\text { Inlet } \\
\text { temperature }\end{array}$ & $\begin{array}{l}\text { Turbulence } \\
\text { model }\end{array}$ & Mesh & $\begin{array}{l}\text { Energy } \\
\text { transfer wall } \\
\text { boundary } \\
\text { condition }\end{array}$ \\
\hline Very low & $1050 \mathrm{~K}$ & Standard k- $\varepsilon$ & Small & Heat loss \\
\hline Low & $1115 \mathrm{~K}$ & Standard k- $\varepsilon$ & Small & Adiabatic \\
\hline Low & $1115 \mathrm{~K}$ & Standard k- $\varepsilon$ & Small & Heat loss \\
\hline Low & $1115 \mathrm{~K}$ & SST k- $\omega$ DES & Medium & Heat loss \\
\hline Medium & $1177 \mathrm{~K}$ & Standard k- $\varepsilon$ & Small & Heat loss \\
\hline Medium & $1177 \mathrm{~K}$ & SST k- $\omega$ DES & Medium & Heat loss \\
\hline High & $1239 \mathrm{~K}$ & Standard k- $\varepsilon$ & Small & Adiabatic \\
\hline High & $1239 \mathrm{~K}$ & Standard k- $\varepsilon$ & Small & Heat loss \\
\hline High & $1239 \mathrm{~K}$ & SST k- $\omega$ & Small & Heat loss \\
\hline High & $1239 \mathrm{~K}$ & SST k- $\omega$ DES & Medium & Heat loss \\
\hline High & $1239 \mathrm{~K}$ & SST k- $\omega$ DES & Large & Heat loss \\
\hline Very high & $1300 \mathrm{~K}$ & Standard k- $\varepsilon$ & Small & Heat loss \\
\hline
\end{tabular}

Table 4. Overview of CFD cases. Mesh sizes (small, medium, large) correspond to the three different mesh resolutions mentioned in Table 2. 


\section{Nomenclature}

\section{Latin letters}

A

$b$

$C_{\text {des }}$

$C_{i}$

$C_{1 \varepsilon}$

$C_{2 \varepsilon}$

$C_{\mu}$

$D_{i}$

E

$E_{a}$

$F_{1}$

$F_{2}$

$F_{D E S}$

$F_{S S T}$

$f_{\beta}$

$f_{\beta^{*}}$

$h$

$k$

$k_{t}$

$k_{t, t}$

$L_{t}$

$r_{n}$

$u$

$\bar{u}$

$u^{\prime}$

$N$

$p$

$R$

$R_{i}$

$S$

$S_{x}$

$S_{i j}$

$S c_{t}$

$t$

$x$

$Y$

Arrhenius pre-exponential factor

Arrhenius temperature exponent

calibration constant $(0.61)$

concentration of species $i\left[\mathrm{~mol} / \mathrm{m}^{3}\right]$

model constant (1.44)

model constant (1.92)

model constant (0.09)

mass diffusivity of species $i\left[\mathrm{~m}^{2} / \mathrm{s}\right]$

specific energy $[\mathrm{J} / \mathrm{kg}]$

activation energy $[\mathrm{J} / \mathrm{mol}]$

blending function

blending function

DES modification function

blending function

model function

model function

enthalpy [J/kg]

turbulent kinetic energy $\left[\mathrm{m}^{2} / \mathrm{s}^{2}\right]$

thermal conductivity [W/m,K]

turbulent thermal conductivity $[\mathrm{W} / \mathrm{m}, \mathrm{K}]$

turbulent length scale [m]

reaction rate for reaction $n\left[\mathrm{~mol} / \mathrm{m}^{3}, \mathrm{~s}\right]$

velocity $[\mathrm{m} / \mathrm{s}]$

average velocity $[\mathrm{m} / \mathrm{s}]$

fluctuating velocity $[\mathrm{m} / \mathrm{s}]$

number

pressure $[\mathrm{Pa}]$

universal gas constant

reaction rate $\left[\mathrm{kg} / \mathrm{m}^{3}, \mathrm{~s}\right]$

strain-rate magnitude [1/s]

source term for $x$

strain-rate tensor $[1 / \mathrm{s}]$

turbulent Schmidt number (0.7)

time [s]

coordinate direction $[\mathrm{m}]$

mass fraction

\section{Greek letters}

$\alpha$

model function

$\alpha^{*} \quad$ low-Reynolds number correction function

$\alpha_{i, n} \quad$ stoichiometric coefficient of reactant $i$ in reaction $n$

$\beta \quad$ model function 


$\begin{array}{ll}\beta^{*} & \text { model function } \\ \Delta & \text { local grid spacing } \\ \varepsilon & \text { turbulent kinetic energy dissipation rate }\left[\mathrm{m}^{2} / \mathrm{s}^{3}\right] \\ v & \text { kinematic viscosity }\left[\mathrm{m}^{2} / \mathrm{s}\right] \\ \rho & \text { density }\left[\mathrm{kg} / \mathrm{m}^{3}\right] \\ \sigma_{k} & \text { model constant }(1.0) \\ \sigma_{k f} & \text { model function } \\ \sigma_{\varepsilon} & \text { model constant }(1.3) \\ \sigma_{\omega} & \text { model function } \\ \sigma_{\omega, 2} & \text { model constant }(1.168) \\ \tau & \text { residence time }[\mathrm{s}] \\ \omega & \text { turbulent kinetic energy specific dissipation rate }\left[\mathrm{s}^{3} / \mathrm{m}^{2}\right]\end{array}$

\section{Subscripts and superscripts}

$\begin{array}{ll}H & \text { heat } \\ i & \text { species identifier or coordinate direction identifier } \\ \text { in } & \text { at the reactor inlet } \\ M & \text { momentum } \\ \max & \text { maximum } \\ M S & \text { mass } \\ r & \text { reaction identifier } \\ R S & \text { reactions } \\ \text { out } & \text { at the reactor outlet }\end{array}$

\section{Abbreviations}

CFD computational fluid dynamics

CSTR continuously-stirred tank reactor

DES detached-eddy simulation

LES large-eddy simulation

$\mathrm{NO}_{\mathrm{x}} \quad$ nitrogen oxides

PFR plug-flow reactor

RANS Reynolds-averaged Navier-Stokes

SNCR selective non-catalytic reduction

SST shear-stress transport 
Figures and figure captions

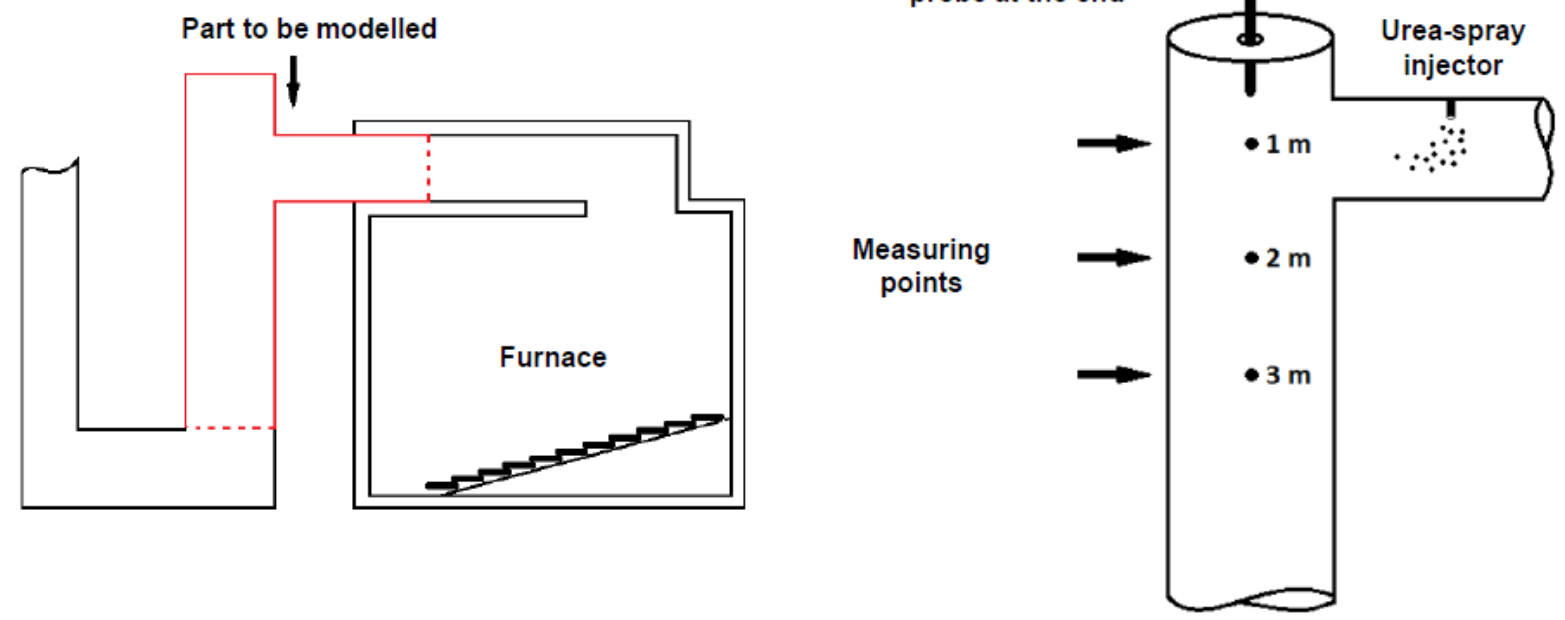

Figure 1. Schematic view of the Rörvik boiler (left) and an illustration of how the measurements were done (right). 


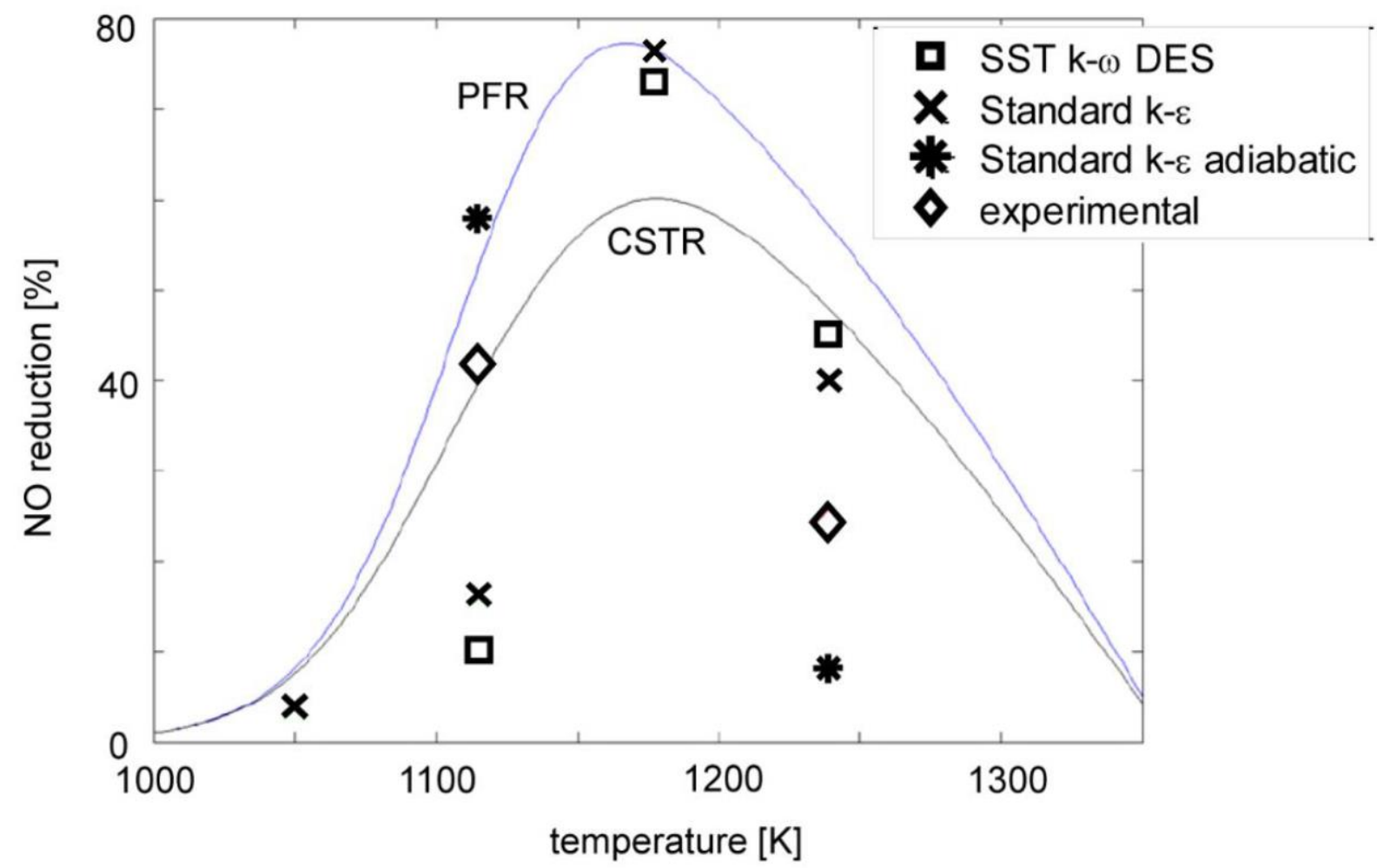

Figure 2. NO reduction versus temperature for the one-dimensional reactor models and the various CFD models considered in this work. The numerical predictions are obtained at the duct center at $h=3 \mathrm{~m}$. 


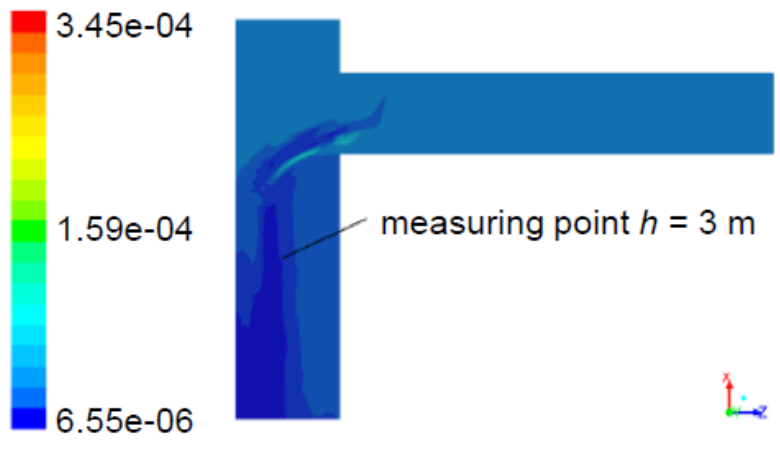

SST k- $\omega$ DES - high temperature

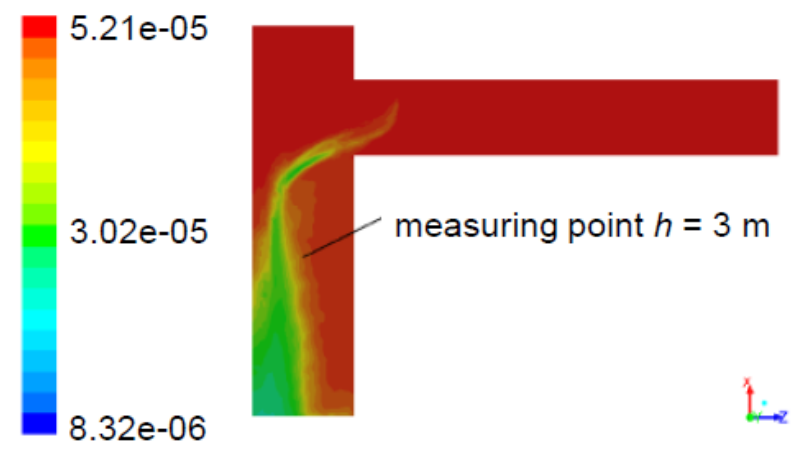

SST k- $\omega$ DES - low temperature

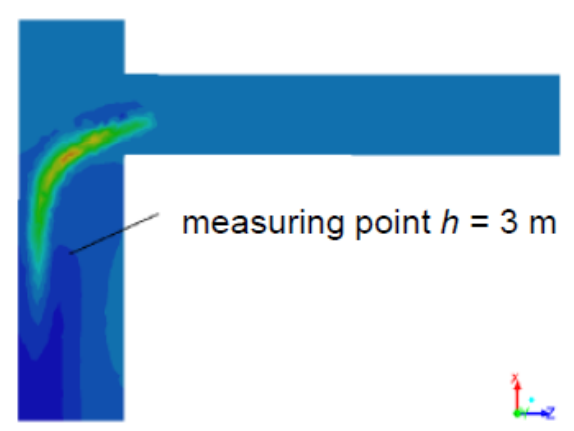

Standard k- $\varepsilon$ - high temperature

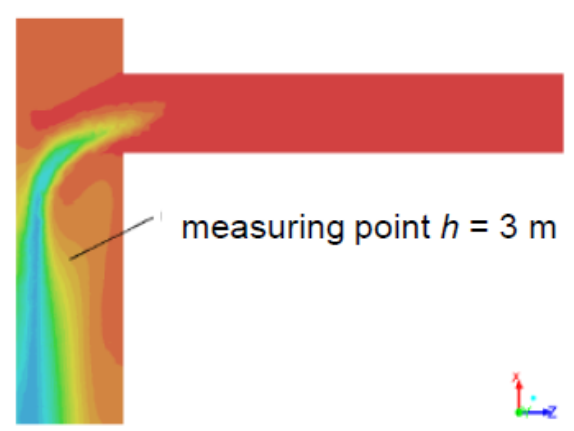

Standard $\mathrm{k}-\varepsilon-$ low temperature

Figure 3. Contour plots of the NO mass fraction in four of the computational cases. 


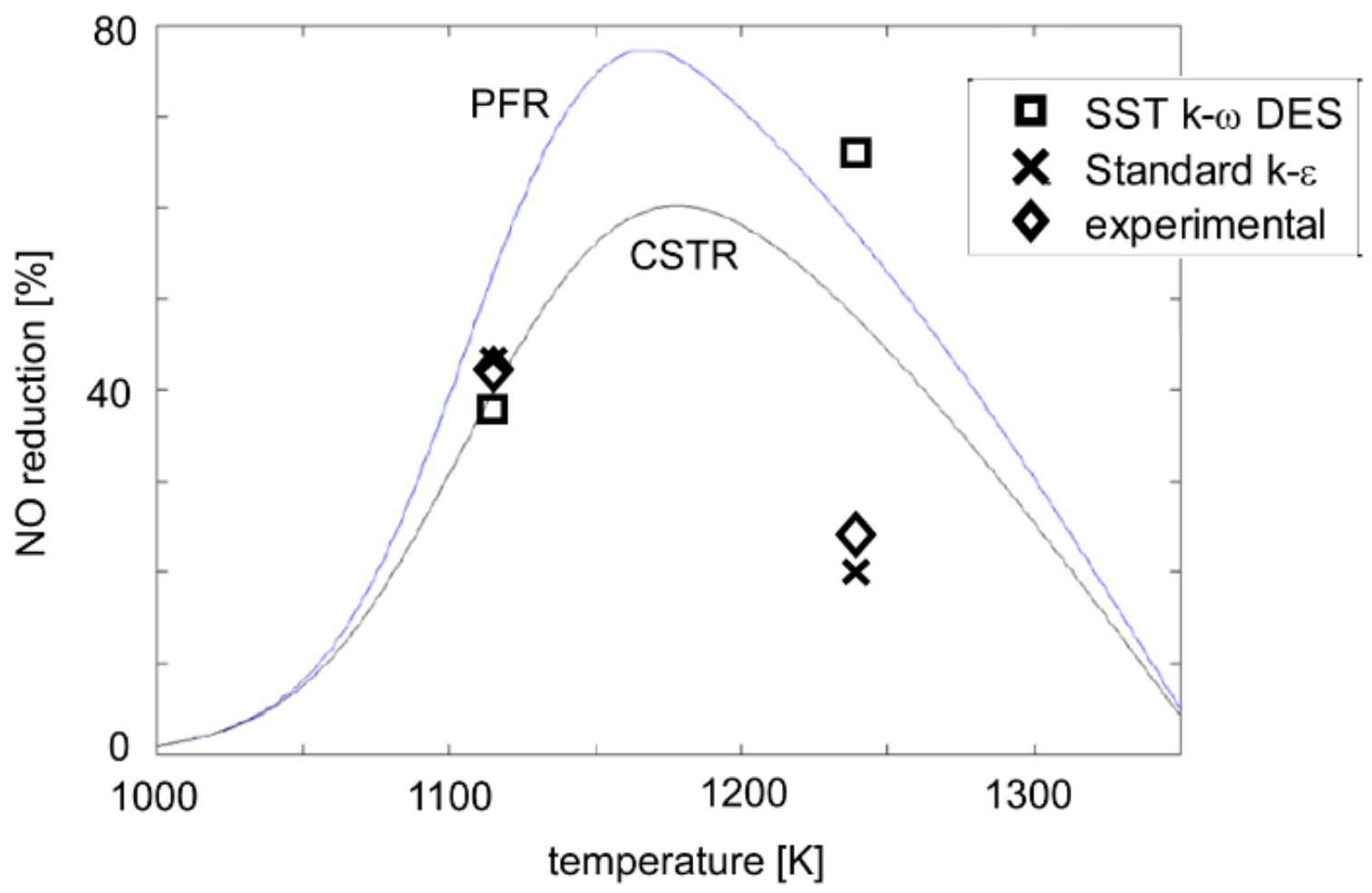

Figure 4. NO reduction versus temperature for the one-dimensional reactor models and the non-adiabatic CFD models considered in this work. The numerical predictions are obtained 30 $\mathrm{cm}$ to the left of the duct center at $h=3 \mathrm{~m}$. 


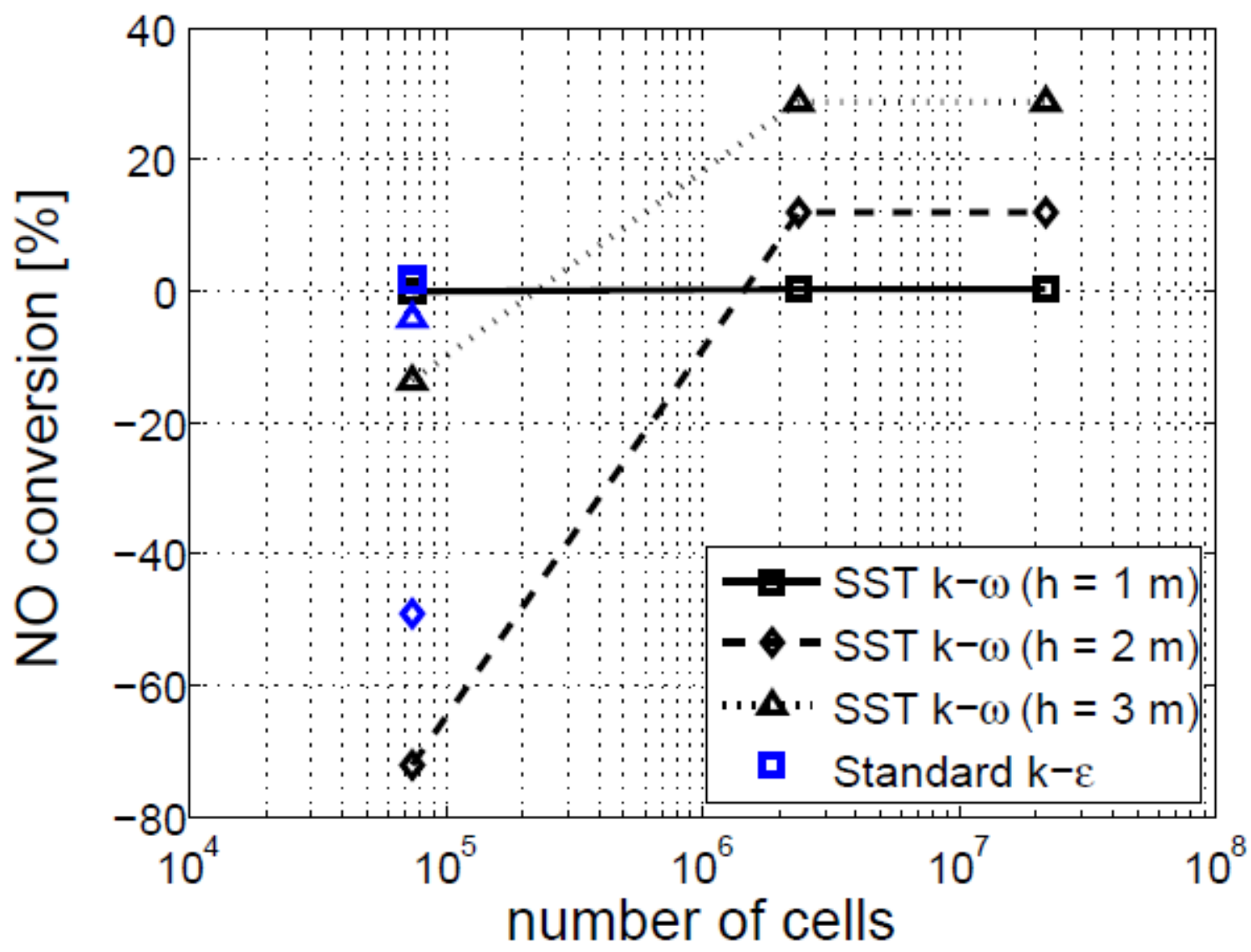

Figure 5. Mass-averaged NO conversion over the duct cross-section at different heights, plotted as a function of the size of the computational grid, for the high temperature case. The coarsest mesh is used with the conventional version of the respective turbulent model, whereas the two finer meshes are detached-eddy simulations. 